Türkiye Tarımsal Araştırmalar Dergisi
http://dergi.sirt.edu.tr $\begin{aligned} & \text { Turk J Agric Res } \\ & \text { (2015) 2: 93-99 } \\ & \text { TÜTAD } \\ & \text { ISSN: 2148-2306 }\end{aligned}$

\title{
Bazı Uçucu Yağ Bileşiklerinin Kanyaş [(Sorghum halepense (L.) Pers.] Gelişimine Etkinliğinin Belirlenmesi
}

\author{
Ayşe YAZLIK ${ }^{1 *}$, İhan ÜREMIş̧ ${ }^{2}$ \\ ${ }^{\text {I} D u ̈ z c e ~ U ̈ n i v e r s i t e s i, ~ Z i r a a t ~ v e ~ D o g ̆ a ~ B i l i m l e r i ~ F a k u ̈ l t e s i, ~ B i t k i ~ K o r u m a ~ B o ̈ l u ̈ m u ̈, ~ D u ̈ z c e, ~ T U ̈ R K i Y E ~}$ \\ ${ }^{2}$ Mustafa Kemal Üniversitesi, Ziraat Fakültesi, Bitki Koruma Bölümü, Hatay, TÜRKIYE
}

\begin{abstract}
Geliș Tarihi/Received: 09.06.2015
Kabul Tarihi/Accepted: 28.09.2015

*Sorumlu Yazar/Correspondence: ayseyazlik77@hotmail.com

Özet: Kanyaş (Sorghum halepense (L.) Pers.) (SORHA) tarım ve tarım dışı alanlarda ciddi verim kayıplarına neden olan çok yıllık yabancı otlardan biridir. Kanyaş tek bir mücadele yöntemi ile kontrol edilemediği için birçok stratejisinin bir arada kullanılması gerekmektedir. Kanyas ile mücadele kullanılabilecek yöntemlerden birisi de allelopatik kimyasalların kullanılmasıdır. Çalışma ile allelokimyasal içeriği olan bitkilerin [İstanbul kekiği (Origanum vulgare L.), lavanta (Lavandula angustifolia L.) ve biberiye (Rosmarinus officinalis L.)] kanyaş gelișimine olan etkisi incelenmiștir. Çıkıș öncesi dönemde biberiye yağının yüksek dozunun $\left(16 \mu 138.465 \mathrm{~cm}^{2}\right)$ en iyi sonucu verdiği ve kanyaş kuru ağırlığını $\% 41.0$ oranında azalttığı tespit edilmiştir. Çıkış sonrası dönemde kullanılan uçucu yağlarda en yüksek etkinin yine $16 \mu 138.465$ $\mathrm{cm}^{2}$ doz (\% 48.0) biberiye uygulamasından sağlandığı tespit edilmiştir. Her üç uçucu yağın da çıkış sonrası uygulamaları çıkış öncesi uygulamalarından daha yüksek etki sağlamıştır.
\end{abstract}

Anahtar Kelimeler: Sorghum halepense (L.) Pers., Origanum vulgare L., Lavandula angustifolia L., Rosmarinus officinalis L., uçucu yağ, alternatif kontrol

\section{Determination of the Efficiency of Some Essential Oil Compounds on the Development of Jonsongrass [(Sorghum halepense (L.) Pers.]}

\begin{abstract}
Jonsongrass (Sorghum halepense (L.) Pers.) (SORHA) is one of the most troublesome perennial weeds caused important yield reductions in the agricultural and environmental problems in the non-agricultural fields. Using a combination of several control strategies is required because Sorha cannot be effectively controlled by a single control method. One of the methods that can be used for the control of Sorha is the usage of allelopathic chemicals. The efficiency of the plants [oregano (Origanum vulgare L.), lavender (Lavandula angustifolia L.) and rosemary (Rosmarinus officinalis L.)] that have allelochemicals on the SORHA were examined with this study. Using rosemary oil at the high rate $(16 \mu 1$ $38.465 \mathrm{~cm}^{2}$ ) gave the best results and reduced dry weight at $41.0 \%$ when it was applied as pre-emergence. The same essential oil rate obtained from rosemary was the highest adversely effects on the Sorha growth (48.0\%) when it was used as post-emergence. Post-emergence application of all three volatile oils has provided more influence on the Sorha growth compared to the pre-emergence application.
\end{abstract}

Keywords: Sorghum halepense (L.) Pers., Origanum vulgare L., Lavandula angustifolia L., Rosmarinus officinalis L., essential oil, alternative control

\section{Giriş}

Yabancı otların ürün miktarı ve kalitesine olumsuz etkileri çok sayıda çalışmada (Güncan, 1979; Uygur ve ark., 1986; Özer ve ark., 2001; Zimdahl,
2007) vurgulanmıștır. Yabancı otlar ile mücadelede pek çok yöntem bulunmasına rağmen öncelikli kullanılan yöntem kimyasal (herbisit) kullanımıdır. Herbisitlerin gerek kullanım kolaylığı gerekse hızlı sonuç vermesi genel tercih 
sebebidir. Ancak uzun vadede doğrudan/dolaylı pek çok yan etkiye de sebep olmaktadır. Dünya genelinde kullanılan pestisit miktarlarına bakıldığında herbisit kullanımı ileri ülkelerde birinci suradadır (Grube ve ark., 2011). Bu denli yoğun kullanılan herbisitler; çevresel (sağlık, kirlilik, vb.) risklere ve ekonomik kayılara sebep olmakta ve bilinçsiz kullanımlar ile uzun vadede bitkilerde dayanıklılık oluşturabilmektedir (Zimdahl, 2007; Anonymous, 2013a).

Son yıllarda gerek çevresel tehditlerin artması gerekse sürdürülebilirlik dikkate alınarak, pestisit kullanılmasına sinırlamalar getirilmekte dolayısıyla; hastalık, zararlı ve yabancı otlar ile mücadelede alternatif mücadele konularında yapılan/yapılacak çalışmalara teşvikler artmaktadır (Anonymous, 2013b).

Alternatif mücadele kapsamında göz önünde tutulması gereken kaynaklardan biri de uçucu yağların kullanımıdır. Uçucu yağların bir çoğu Apiaceae, Lamiaceae, Myrtaceae ve Rutaceae familyasında yer alan aromatik bitki türlerinde bulunmaktadır (Başer, 1993). Bu bileşiklerin bitkilerde yüksek oranda fitotoksik etkiye sahip olduğu, herbisit etkilerinin organik tarımda kullanılabilecek formülasyonların geliştirilmesi için çalışılması ve bu çalışmaların devamlılığının da önemli olduğu çok sayıdaki araştırıcı tarafından da vurgulanmaktadır (Duke ve ark., 2002; Tworkoski, 2002; Luciana ve ark., 2003; Arminante ve ark., 2006; Dayan ve ark., 2009; Üremiş ve ark., 2009a; Efil, 2012).

İstilacı karakteri nedeni ile pek çok alanda zarar seviyesini her geçen gün arttıran bitkilerden biri olan kanyaş [Sorghum halepense (L.) Pers.] (SORHA) çok yıllık bitkilerden biridir. Örneğin; Marmara bölgesi genelinde SORHA yoğunluğunun; $\mathrm{m}^{2}$, de 13.40-30.12, rastlanma sıklığının ise \% 34.20-100 arasında değiştiği tespit edilmiştir (Yazlık, 2014). Ayrıca ülkemizin farklı bölge ve alanlarında yapılan surveylere bakıldığında da kanyaşın bulaşık olduğu her kültür ve alanda en fazla rastlanılan türlerden biri olduğu görülmektedir (Uygur ve Koch, 1990; Tepe, 1992; Kadığlu ve ark., 1993; Uluğ ve ark., 1993; Uluğ ve Kadığlu, 1995; Erten ve Nemli, 1997; Boz, 2000; Kaya ve Nemli, 2001; Kadığlu ve ark., 2004; Tursun ve ark., 2004; Gözcü ve Uludağ, 2005; Tursun ve Seyithanoğlu, 2006; Uludağ ve ark., 2007; Üremiş ve ark., 2009a). Kültür bitkisi ekim alanlarında kanyaş gibi çok yıllık ve rizomlu yabancı otların mücadelesinde; küçük alanlarda elle yolma şeklinde mücadele edilmeye çalışıldı̆̆ 1 , seçici dar yapraklı herbisitlerin kullanıldığı, ancak her kültürde/alanda kanyaşa karşı kullanılabilecek etkili bir herbisitin bulunmadığı (Uygur ve ark.,1986; Özer ve ark., 2001, Güneş ve ark., 2008; Üremiş ve ark., 2009a), ayrıca kanyaş bitkisinde herbisitlere dayanıklılık sorununun olduğu (Anonymous, 2013a) da bildirilmektedir. Bu durumlar dikkate alınarak kanyaşın alternatif mücadele yöntemlerinin araştırılması önem taşımaktadır.

Kanyaşın mücadelesinde çeşitli alternatif mücadele çalışmaları yapılmaktadır (Uygur ve ark., 1988; Uygur ve ark., 1991; Cheema, 2000 ve 2001; Tworkoski, 2002; Doğan ve Uygur, 2005; Üremiş, 2006; Üremiş ve ark., 2009a; Anonymous, 2013c; Yazlık, 2014). Bu çalışmalar da öncelikli amaç kanyaşa karşı kullanılan bitki/bitkilerin etkinliğinin var olup olmadığını belirlemek ve etkinliğin tespit edildiği bitki/bitki grupları ile de çalışmaların devamlılığını sağlayabilecek veriler elde etmektir. $\mathrm{Bu}$ yönde yapılan çalışmaların artması, uçucu yağ ihtiva eden bitki çeşitliliğinin etkinliği ve hedef alınan/alınacak organizmaların çeşitliliği dikkate alındığında, önem taşımaktadır. Özellikle bu durum da dikkate alınarak planlanan bu çalışmanın amacı, İstanbul kekiği (Origanum vulgare L.), lavanta (Lavandula angustifolia L.) ve biberiye (Rosmarinus officinalis L.) bitkilerine ait uçucu yağların kanyaş gelişimine etkisini belirlemektir.

\section{Materyal ve Yöntem}

\subsection{Materyal}

Çalışmanın ana materyallerini; kanyaş (Sorghum halepense (L.) Pers., bitkisinin rizomları, çeşitli laboratuvar malzemeleri, İstanbul kekiği (Origanum vulgare L.), lavanta (Lavandula angustifolia L.), biberiye (Rosmarinus officinalis L.) bitkilerine ait uçucu yağlar, mantolu isitıcı ve neo-clevenger aparatı oluşturmaktadır.

\subsection{Yöntem}

Uçucu yağ elde edilen İstanbul kekiği (Origanum vulgare L.), İngiliz lavantas1 (Lavandula angustifolia L.) ve biberiye (Rosmarinus officinalis L.) bitkileri 2012 yılının Haziran-Eylül aylarında çiçeklenme döneminde toprak seviyesinden itibaren biçilerek $24{ }^{\circ} \mathrm{C}$ 'de gölgede kurutulmuştur. Uçucu yağ elde etmek için 500 gram kurutulmuş bitki örneği 6 litrelik cam balonlara konulmuş, üzerine 4 litre su ilave edilerek mantolu 1sitıcıya yerleştirilmiş ve 200 ${ }^{\circ} \mathrm{C}$ 'de yaklaşık 180 dakika kaynatılmıştır. Neoclevenger'de toplanan uçucu yağ mikro pipet yardımıyla alınmış ve koyu renkli cam şişelere konulmuştur (Efil, 2012).

Tüm uçucu yağ denemeleri $180 \mathrm{~cm}^{3}$ hacimli pet bardaklarda, tesadüf parselleri deneme 
desenine göre 6 tekerrürlü ve 2 tekrarlamalı olarak sicaklığı ve nem oranı ayarlanabilen iklim odasında kurulmuştur. Pet kaplar içerisine 1/3 oranında dere kumu içeren killi-tınlı yapıya sahip steril toprak konulmuştur. Denemelerde kontrol dâhil 5 uygulama $\left(0,2,4,8\right.$ ve $\left.16 \mu 138.465 \mathrm{~cm}^{2}\right)$ yer almış ve kontrol kaplarına sadece saf su verilmiştir. Uygulamada kullanılan uçucu yağların hazırlığında; uygulama dozunda uçucu yağ + uçucu yağların kolaylıkla çözünmesini sağlamak için etanol-\% 70 (uygulama dozu ile aynı oranda) + köpürmeyi engellemek için $30 \mu$ lween-20 + bitkide tutunmayı sağlamak için susam yağ (uygulama dozu ile aynı oranda) + saf su kullanılmıştır (Efil, 2012).

Değerlendirmeler 28 gün sonra yapılmıştır. Değerlendirmelerde kültür bitkisi uygulamalarında bitkilerin kök uzunlukları ölçülmüş ve kuru ağırlıkları belirlenmiş, kanyaşa karşı yapılan uygulamalarda ise bitki kuru ağırlığı belirlenmiştir. Kuru ağırlıkların belirlenebilmesi için bitkiler 60 ${ }^{\circ} \mathrm{C}$ 'de 48 saat etüvde kurutulmuştur. İki tekrarlama arasında istatistikî olarak fark görülmediğinden veriler birleştirilerek kullanılmıştır. Ayrıca tüm uygulamalardan elde edilen sonuçların etki oranları aşağıda belirtilen Eşitlik-1 (Abbott formülü)'e göre hesaplanmıştır.

$$
\mathrm{EO}=[(\mathrm{K}-\mathrm{C}) / \mathrm{K}] \times 100
$$

$\mathrm{EO}=$ Etki Oranı $(\%)$

$\mathrm{K}=$ Kontroldeki miktar (adet, gram, ölçüm..vs.)

$\mathrm{C}=$ Ekstrakt / kuru madde eklenmiş ortamda çimlenme (adet, gram, ölçüm..vs.)

Denemelerde kanyaş rizomlarındaki apikal dominansı ortadan kaldırmak amacı ile 2-3 cm boyunda tek boğum içeren bir adet rizom parçası kullanılmıştır.

Çıkış öncesi uygulamalar: Hazırlanan rizomların dikimleri yapılmış ve çıkış görülmeden uçucu yağ içeren önceden hazırlanmış çözeltiler ayrı ayrı uygulanmıştır.

Çıkış sonrası uygulamalar: Hazırlanan rizomların dikimleri yapılmış ve fide boyu 5-10 cm ulaştı̆̆ı dönemde, uçucu yağ içeren önceden hazırlanmış çözeltiler modifiye edilmiş havalı boya tabancası ile $20 \mathrm{lda}^{-1}$ ilaçlama normunda 2 , 4, 8 ve $16 \mu \mathrm{l} 38.465 \mathrm{~cm}^{2}$ dozlarında yaprağa püskürtme şeklinde uygulanmıştır. Kontrollere ise sadece saf su uygulanmıştır. Bitkiler dört hafta sonra hasat edilerek bitki kök kuru ağırlıkları belirlenmiştir.

Denemelerden elde edilen verilere varyans analizi yapılmış, gruplar arası farklılıklar Duncan çoklu karşılaştırma testi ile belirlenmiştir $(\mathrm{p}<0.05)$.
İstatistiksel değerlendirmeler SPSS 13.0 istatistik programı kullanılarak yapılmıştır.

\section{Bulgular ve Tartışma}

\section{1. Çıkış öncesi uygulamalar}

Hazırlanan rizomların dikimleri pet bardaklara yapılmış ve çıkış görülmeden önce uçucu yağ içeren çözeltiler ayrı ayrı uygulanmış ve elde edilen sonuçların etki oranları (\%) hesaplanmıştır.

Kekik, lavanta ve biberiyeden elde edilen uçucu yağ uygulamalarında kanyaş bitkisinin kuru ağırlığının istatistikî yönden önemli derecede etkilediği ve uçucu yağ doz artışına paralel olarak genel anlamda kanyaşta gelişme geriliği olduğu belirlenmiştir. Elde edilen sonuçlar incelendiğinde kekiğin; 0,2 ve $4 \mu 138.465 \mathrm{~cm}^{2}$ uçucu yağ dozları arasında istatistikî yönden farklılık bulunmamaktadır. Ancak 8 ve $16 \mu 138.465 \mathrm{~cm}^{2}$ uçucu yăg uygulamalarının istatistikî bakımdan aynı grubu oluşturduğu, $16 \mu 138.465 \mathrm{~cm}^{2}$ dozunun kanyaş kuru ağırlığını \% 23 oranında etkilediği tespit edilmiştir. Lavanta uçucu yağına ait uygulama dozlarına bakıldığında; $2 \mu 138.465 \mathrm{~cm}^{2}$ uygulama dozu hariç diğer uçucu yağ dozlarının kontrole göre kanyaş kuru ağırlığı üzerinde olumsuz etkide bulunduğu belirlenmiştir. En etkili bulunan $16 \mu \mathrm{l} 38.465 \mathrm{~cm}^{2}$ uçucu yağ dozundan kanyaş kuru ağırlığının kontrole göre \% 19 oranında azaldığ 1 tespit edilmiştir. Biberiyeden elde edilen uçucu yağların etkileri incelendiğinde ise kekik uçucu yağına benzer etkileri olduğu, yani 8 ve $16 \mu 138.465 \mathrm{~cm}^{2}$ uçucu yağ uygulamalarının istatistikî bakımdan aynı grubu oluşturduğu ancak etki oranına bakıldığında $16 \mu \mathrm{l} 38.465 \mathrm{~cm}^{2}$ dozunun kanyaş kuru ağırlığını \% 41 oranında gerilettiği belirlenmiştir (Tablo 1). Yapılan tüm uygulamalar arasında en etkili sonuç bu uygulamadan elde edilmiştir.

\section{2. Çıkış sonrası uygulamalar}

Hazırlanan kanyaş rizomlarının dikimleri yapılmış ve fide boyu $10 \mathrm{~cm}$ ulaştığı dönemde uçucu yağ içeren çözeltiler ayrı ayrı uygulanmış ve elde edilen sonuçların etki oranları (\%) hesaplanmıştır (Tablo 2).

Uygulamaların etki oranlarına bakıldığında kanyaşın artan doza paralel olarak tüm uçucu yağlardan etkilendiği tespit edilmiştir. Uygulama dozları arasında en etkili doz kekik ve lavantada 8 $\mu 138.465 \mathrm{~cm}^{2}$ ve $16 \mu 138.465 \mathrm{~cm}^{2}$ dozlarda, biberiyede ise $16 \mu \mathrm{l} 38.465 \mathrm{~cm}^{2}$ dozdan elde edilmiştir. Etki oranlarına bakıldığında $16 \mu \mathrm{l}$ $38.465 \mathrm{~cm}^{2}$ doz da biberiyeden \% 48.0, lavantadan \% 44.0 ve kekik de ise \% 36.0 kanyaş kuru ağırlığının etkilediği belirlenmiştir. 
Tablo 1. Çıkış öncesi uçucu yağ uygulamalarının kanyaş kuru ağırlığına etkileri (g)

\begin{tabular}{|c|c|c|c|c|c|c|}
\hline \multirow[t]{2}{*}{ Uygulama } & \multicolumn{2}{|c|}{ Kekik } & \multicolumn{2}{|c|}{ Lavanta } & \multicolumn{2}{|c|}{ Biberiye } \\
\hline & Ortalama* & $\% \mathrm{EO}$ & Ortalama* & $\% \mathrm{EO}$ & Ortalama* & $\% \mathrm{EO}$ \\
\hline Kontrol & $8.20 \mathrm{~A}$ & - & $8.20 \mathrm{~B}$ & - & $8.20 \mathrm{~A}$ & - \\
\hline $2 \mu \mathrm{l} 100 \mathrm{ml}^{-1}$ & $7.50 \mathrm{~A}$ & 9 & $9.30 \mathrm{~A}$ & -13 & $7.80 \mathrm{~A}$ & 5 \\
\hline $4 \mu \mathrm{l} 100 \mathrm{ml}^{-1}$ & $7.17 \mathrm{AB}$ & 13 & $8.00 \mathrm{~B}$ & 3 & $7.33 \mathrm{~A}$ & 11 \\
\hline $8 \mu \mathrm{l} 100 \mathrm{ml}^{-1}$ & $7.04 \mathrm{~B}$ & 14 & $7.60 \mathrm{~B}$ & 7 & $5.60 \mathrm{~B}$ & 32 \\
\hline $16 \mu 1100 \mathrm{ml}^{-1}$ & $6.31 \mathrm{~B}$ & 23 & $6.70 \mathrm{C}$ & 19 & $4.87 \mathrm{~B}$ & 41 \\
\hline
\end{tabular}

Tablo 2. Çıkış sonrası uçucu yağ uygulamalarının kanyaş kuru ağırlığına etkileri (g)

\begin{tabular}{|c|c|c|c|c|c|c|}
\hline \multirow[t]{2}{*}{ Uygulama } & \multicolumn{2}{|c|}{ Kekik } & \multicolumn{2}{|c|}{ Lavanta } & \multicolumn{2}{|c|}{ Biberiye } \\
\hline & Ortalama* & $\% \mathrm{EO}$ & Ortalama* & $\% \mathrm{EO}$ & Ortalama* & $\% \mathrm{EO}$ \\
\hline Kontrol & $11.00 \mathrm{~A}$ & - & $11.00 \mathrm{~A}$ & - & $11.00 \mathrm{~A}$ & - \\
\hline $2 \mu \mathrm{l} 100 \mathrm{ml}^{-1}$ & $9.40 \mathrm{~B}$ & 15 & $7.30 \mathrm{~B}$ & 34 & $7.50 \mathrm{~B}$ & 32 \\
\hline $4 \mu \mathrm{l} 100 \mathrm{ml}^{-1}$ & $9.80 \mathrm{~B}$ & 11 & $7.50 \mathrm{~B}$ & 32 & $6.43 \mathrm{CD}$ & 42 \\
\hline $8 \mu \mathrm{l} 100 \mathrm{ml}^{-1}$ & $7.10 \mathrm{C}$ & 36 & $6.40 \mathrm{C}$ & 42 & $6.50 \mathrm{C}$ & 41 \\
\hline $16 \mu 1100 \mathrm{ml}^{-1}$ & $7.04 \mathrm{C}$ & 36 & $6.20 \mathrm{C}$ & 44 & $5.70 \mathrm{D}$ & 48 \\
\hline
\end{tabular}

EO: Etki oranı (değerlendirmeler uygulamadan 28 gün sonra yapılmııștır)

Elde edilen bu sonuçlardan kekik, biberiye ve lavanta uçucu yağlarının kanyaş gelişimine etkisinin var olduğu belirlenmiştir. Yapılan deneme sonuçları incelendiğinde, uygulama zamanının ve dozunun değişimi etki oranını daha yüksek oranlara çıkarabileceği kanaatine varılmıştır. Nitekim uygulama zamanının etkinlik değerlerini değiştirdiği Abouziena ve ark. (2009) tarafından yapılan bir çalışmada vurgulanmıştır.

Kekik (Origanum vulgare L.), lavanta (Lavandula angustifolia L.) ve biberiye (Rosmarinus officinalis L.) türlerinin kanyaş gelişimine etkilerin belirlendiği bu çalışma dışında farklı bir çalışmaya rastlanılmamıștır. Dolayısıyla uçucu yağı kullanılan bu bitkilerin etkinliği ilk kez bu çalışma ile ortaya konulmuştur.

Lamiaceae familyası üyelerinin de bulunduğu bir çalışmada (Tworkoski, 2002); Thymus vulgaris, Syzgium aromaticum, Cinnamomum zeylanicum ve Satureja hortensis bitkilerine ait uçucu yağlar Sorghum halepense, Chenopodium album, Ambrosia artemisiifolia ve Taraxacum officinale bitkilerine karşı uygulanmıştır. Kullanılan bu yağlar tüm yabancı otlar üzerinde etkili bulunmuştur. Kanyaş bitkisi için uygulamalar, bitki boyunun 25-30 cm olduğu dönemde, yapılmış ve uygulama sonrasında tüm uçucu yağların kanyaş üzerinde etkinliğini tespit edilmiştir. Araştırıcı uçucu yağlarının bitkilerde elektrolit sızıntısına yol açarak hücre ölümlerine yol açmalarından dolayı yüksek oranda fitotoksik etkiye sahip olduğunu bildirmiştir. Ayrıca uçucu bileşiklerin herbisit etkilerinin organik tarımda kullanılabilecek formülasyonlar için çalışmaların devamlılığının önemli olduğunu da vurgulamıștır. Uçucu yağların kanyaş gelişimine etkinliği konusunda daha farklı başka bir çalışmaya rastlanılamamıştır. Ancak yine Lamiaceae familyası üyeleri ile yapılan bir çalışmada (Üremiş ve ark., 2009b), fesleğen (Ocimum basilicum), lavanta (Lavandula angustifolia), adi kekik (Thymus vulgaris), adaçayı (Salvia officinalis) ve oğul otundan (Melissa officinalis) elde edilen uçucu yağların domuz pitrağı (Xanthium strumarium), kısa başaklı kuşyemi (Phalaris brachystachys) ve kisır yabani yulaf (Avena sterilis)'ın çimlenmesini ve bitki gelişimlerini engellediği belirlenmiştir. Farklı bir çalışmada ise (Efil, 2012) dağ kekiği (Origanum syriacum L.) ve mercanköşk (Origanum majorana L.)'ten elde edilen uçucu yağların ve hidrosollerin, Amaranthus retroflexus L., Echinochloa colonum (L.) Link, Portulaca oleracea L., Physalis angulata L. ve Solanum nigrum L. ile kültür bitkilerinden pamuk, misir, domates, marul ve maydanoz tohumlarının çimlenmesi ve bitki gelişimine etkisi incelenmiştir. Çimlenme çalışmalarında, her iki uçucu yağ uygulamasının da yabancı otların tohum çimlenmelerini ortalama \% 50'nin üzerinde engellediği, kültür bitkilerinde ise misır tohumlarının uygulamalardan en az etkilenen bitki olduğu vurgulanmıştır. Uçucu yağların bitki büyümesine etkileri incelendiğinde ise, $P$. oleracea ve $S$. nigrum'un gelișimi $\% 50$ üzerinde engellenirken, kültür bitkilerinde yapılan uygulamalarda $L$. sativa oldukça hassas olduğu bulunmuştur. Araştırıcılar uçucu yağların yabancı ot tohumlarının çimlenmesi üzerinde güçlü bir engelleyici etkilerinin olduğu ve bu etkilerin etki mekanizmalarının anlaşılması için çalışmaların devamlılığına ihtiyaç olduğunu da ayrıca vurgulamaktadir.

Sentetik kimyasallara alternatif olabilecek uçucu yağ bileşiklerine yönelik çalışmalar bu 
bileşiklerin etki tespitine, etken maddenin ve etki mekanizmasının anlaşılabilmesine olanak sağlar. Allelokimyasalların doğal çevreyi, alıcı organizmaları etkileme şeklinin araştırılması ve ekili alanlarda allelokimyasal kullanımı için pratik yollar bulunmasının önemi de vurgulanmaktadır (Rimando ve ark., 2005; Inderjit ve ark., 2009). Ayrıca doğal yollardan elde edilen herbisitlerin birçok farklı etki mekanizmasına sahip olabileceği ve etki mekanizmalarının moleküler düzeyde amino asit, nükleik asit ve lipit sentezi gibi çeşitli biyokimyasal yollarla olabileceği bildirilmiştir (Duke ve ark., 2002). Uçucu yă̆ bileşikleri kullanılarak yapılan çalışmalar henüz çok yeni olmasına rağmen pek çok uçucu yağın hedef alınan canlılara etkilerinin tespiti konusunda çalışmalar yapılmakta ancak, bu çalışmalar gerek mevcut uçucu yağ ihtiva eden bitki çeşitliliği gerekse hedef alınacak organizmaların çeşitliliği dikkate alındığında yetersiz kalmaktadır (Işık ve ark., 2013).

\section{Sonuçlar}

Bu çalışmada kekik, lavanta ve biberiye uçucu yağlarının kanyaş gelişimine etkileri değerlendirildiğinde en iyi etki oranı çıkış öncesi dönemde \% 41.0 ve çıkış sonrası dönemde ise \% 48.0 oranlar ile biberiyeden sağlanmıştır. Elde edilen sonuçlar kanyaş gelişimine uçucu yağların etkinliği konusunda yapılan çalışmalara destek sağlayacaktır. Ayrıca sonuçlar çalışmaların en etkili bulunan Rosmarinus officinalis üzerinden devam ettirilmesi bakımından da önem taşımaktadır. Nitekim en iyi sonucu elde ettiğimiz Rosmarinus officinalis'in; insektisit ve fungusit etkisi konusunda ruhsatlı ilaçlar elde edildiği ayrıca içermiş olduğu 1.8 -cineole $\quad\left(\begin{array}{ll}\% & 25.0\end{array}\right.$ oranında), borneol, kâfur ve yüksek miktarda monoterpen bileşiklerinin herbisit etkinliği olduğu (Dayan ve ark., 2009) dikkate alındığında elde edilen sonuçlar ümit var görülmektedir.

Çalışma ile bağlantılı olarak belirtilmelidir ki, uçucu yağ bileşiği elde edilen bitkilerin yetiştikleri yerlerdeki iklim koşulları ve stres faktörleri gibi sebeplerden dolayı içerdikleri etken madde oranlarındaki azalış veya artış kullanılan uçucu yağlarda farklılıklara sebep olabilir (Abouziena ve ark., 2009; Işık ve ark., 2013). Ayrıca uçucu yağların etkin ve yaygın bir şekilde kullanılabilmesi için; (i) uygun formülasyon, (ii) uygun alet ve makine, (iii) bitki üzerinde tutunmayı sağlayacak uygun yayıcı yapıştırıcı, (iv) uygulama şekli, (v) bekleme süresi, (vi) uygulanabilecek toprağın durumu (nem, sicaklık, toprak tipi), (vii) sıcaklığa uygun formülasyon ve (viii) uygun doz konularında eş zamanlı çalışmalar yapılması (Işık ve ark., 2013) çalışmaların çok disiplinli bir şekilde yürütülmesi, sonuca giden yolun kısaltması bakımından önemlidir.

\section{Teşekkür}

$\mathrm{Bu}$ çalışmanın yapılmasına maddi katkı sağlayan Tarımsal Araştırmalar ve Politikalar Genel Müdürlüğü (TAGEM)'ne, Mustafa Kemal Üniversitesi Bilimsel Araştırma Projeleri Komisyonu'na (MKÜ-BAP-1105D0101) ve istatistikî verilerin değerlendirilmesindeki yardımlarından dolayı Dr. Ahmet Tansel SERIM'e teşekkür ederiz.

\section{Kaynaklar}

Anonymous, 2013a. Weed science. http://www. weedscience.org/Summary/Species.aspx? WeedID=166 (Erişim tarihi: 08.01.2013).

Anonymous, 2013b. FAO. http:/www.fao.org/ agriculture/crops/agp-home/en/?no_cache=1 (Erişim tarihi: 12.07.2013).

Anonymous, 2013c. ISSG. http://www.issg.org/ (Erişim tarihi: 12.07.2013).

Abouziena, H.F.H., Omar, A.A.M., Sharma, S.D., Singh, M., 2009. Efficacy comparison of some new natural-product herbicides for weed control at two growth stages. Weed Technology, 23(3): 431-437.

Arminante, F., De Falco, E., De Feo, V., De Martino, L., Mancini, E., Quaranta, E., 2006. Allelopathic activity of essential oils from Mediterranean Labiatae. I. International Symposium on the Labiatae: Advances in Production, Biotechnology and Utilisation, 22-25 February, Sanremo-Italy, p. 347-360.

Başer, K.H.C., 1993. Essential oils of Anatolian Labiatae: A profile. Acta Horticulturae, 333: 217238

Boz, Ö., 2000. Aydın ili pamuk ekim alanlarındaki yabancı otların yaygınlık ve yoğunluklarının saptanmas1. Türkiye Herboloji Dergisi, 3(1): 10-16.

Cheema, Z.A., Sadiq, H.M.I., Khaliq, A., 2000. Efficacy of sorgaab (Sorghum water extract) as a natural weed inhibitor in wheat. International Journal of Agriculture \& Biology, 2(1-2): 144-146.

Cheema, Z.A., Khaliq, A., Akhtar, S., 2001. Use of sorgaab (Sorghum water extract) as a natural weed inhibitor in spring mungbean. International Journal of Agriculture \& Biology, 3(4): 515-518.

Dayan, F.E., Howell, J., Weidenhamer, J.D., 2009. Dynamic root exudation of sorgoleone and its in planta mechanism of action. Journal Experimental Botany, 60(7): 2107-2117.

Doğan, A., Uygur, F.N., 2005. Antep turpu (Raphanus sativus L.)'nun misir bitkisine ve yabanc1 ot türlerine olan allelopatik etkisinin araştırılması. Türkiye Herboloji Dergisi, 8(2): 10-25.

Duke, O.S., Dayan, E.F., Rimando, M.A., Schrader, K.K., Aliotta, G., Oliva, A., Romagni, J.G., 2002. 
Chemicals from nature for weed management. Weed Science, 50:138-151.

Efil, F., 2012. Mercanköşk (Origanum majorana L.) ve dağ kekiği (Origanum syriacum L.) uçucu yağ ve hidrosollerinin yabancı otlara karşı biyo-herbisidal potansiyellerinin belirlenmesi. Yüksek lisans tezi, Mustafa Kemal Üniversitesi Fen Bilimleri Enstitüsü, Hatay.

Erten, L., Nemli, Y., 1997. Zeytin fidanlıklarında görülen yabancı otlar ve yoğunluklarının belirlenmesi üzerinde çalışmalar. Türkiye II. Herboloji Kongresi, 1-4 Eylül, Ayvalık-İzmir, s. 133-140.

Grube, A., Donaldson, D., Kiely, T., Wu, L., 2011. Pesticides Industry Sales and Usage Pesticides Industry Sales and Usage Report. U.S. Environmental Protection Agency (EPA) Biological and Economic Analysis Division Office of Pesticide Programs Office of Chemical Safety and Pollution Prevention U.S. Environmental Protection Agency Washington, Page: 5.

Güncan, A., 1979. Tarla sarmaşığı (Convolvulus arvensis)'nın biyolojisi ve buğday içerisinde mücadele imkanları üzerinde araștırmalar. Atatürk Üniversitesi Ziraat Fakültesi Yayınları, No: 234, Araştırma Serisi No: 151, Erzurum.

Güneş, E., Uludağ, A., Üremiş, I., 2008. Economic impact of johnsongrass (Sorghum halepense (L.) Pers.) in cotton production in Turkey. Zeitschrift für Pflanzenkrankheiten und Pflanzenschutz, Sonderheft XXI: 515-520.

Gözcü, D., Uludağ, A., 2005. Kahramanmaraş ile pamuk tarlalarında görülen yabancı ot türleri ve önemi. Türkiye Herboloji Dergisi, 8(1): 7-15.

Inderjit, Kaur, R., Kaur, S., Callaway, R.M., 2009. Impact of $( \pm)$-catechin on soil microbial communities. Communicative \& Integrative Biology, 2(3): 1-3.

Işı1k, A., Arslan, M., Efill, F., Üremiş, İ., Uludağ, A., 2013. Uçucu yağların Türkiye'de yabancı ot mücadelesinde kullanılabilirliğinin değerlendirilmesi. I. Bitki Koruma Ürünleri ve Makineleri Kongresi, 2-5 Nisan, Side-Antalya, Cilt I, s. 229-241.

Kadıoğlu, İ., Uluğ, E., Üremiş, İ., 1993. Akdeniz bölgesi pamuk ekim alanlarinda görülen yabanci otlar üzerinde araştirmalar. Türkiye I. Herboloji Kongresi, 3-5 Şubat, Adana, s. 151-156.

Kadıoğlu, İ., Üremiş, İ., Uludağ, A., 2004. Relationships between seed bank and weed flora in cotton areas in the Cukurova Region of Turkey. Bulletin of Pure and Applied Science, 23(1): 61-69.

Kaya, İ., Nemli, Y., 2001. Aydın ili önemli pamuk ekiliş alanlarında sorun olan yabanc1 otların saptanması. Yüzüncü Yıl Üniversitesi Ziraat Fakültesi Tarım Bilimleri Dergisi, 12(1): 37-40.

Luciana, A.G., Carpenese, G., Ciani, P.L., Morelli, I., Macchia, M., Flamini, G., 2003. Essential oils from Mediterranean Lamiaceae as weed germination inhibitors. Journal of Agricultural and Food Chemistry, 51(21): 6158-6164.
Özer, Z., Kadıŏlu, İ., Önen, H., Tursun, N., 2001. Herboloji (Yabanc1 Ot Bilimi). Gaziosmanpaşa Üniversitesi Ziraat Fakültesi Yayınları, No:20, Kitaplar Serisi No:10, Tokat.

Rimando, A.M., Kagan, I.A., Dayan, F.E., Czarnota, M.A., Weston, L.A., 2005. Chemical basis for weed suppressive activity of sorghum. In: Petroski RJ, Tellez MR, Behle RW, editors. Semiochemicals in Pest and Weed Control. Washington DC: American Chemical Society, pp. 59-70.

Tepe, I., 1992. Domates fideliklerinde sorun olan yabanc1 otlar ve kimyasal mücadeleleri üzerinde araştırmalar. Doktora tezi, Ege Üniversitesi Fen Bilimleri Enstitüsü, İzmir.

Tursun, N., Tursun, A.Ö., Kaçan, K., 2004. Kahramanmaraş ili ve ilçelerinde pamuk ekim alanlarında sorun olan yabancı otların belirlenmesi. Kahramanmaraş Sütçü İmam Üniversitesi Fen ve Mühendislik Dergisi, 7(1): 92-95.

Tursun, N., Seyithanoğlu, M., 2006. Kahramanmaras ilinde önemli kültür bitkilerinde sorun olan önemli yabancı ot türleri ve bunlarla mücadelede en yaygın kullanilan herbisitlerin belirlenmesi. Kahramanmaraş Sütçü Imam Üniversitesi Fen ve Mühendislik Dergisi, 9(2): 116-120.

Tworkoski, T., 2002. Herbicide Effect of Essential Oils. Weed Science, 50(4): 425-431.

Uludağ, A., Gözcü, D., Ruşen, M., Güvercin, R.S., Demir, A., 2007. The effect of johnsongrass (Sorghum halepense (L.) Pers.) densities on cotton yield. Pakistan Journal of Biological Sciences, 10(3): 523-525.

Uluğ, E., Kadioğlu, İ., Üremiş, İ., 1993. Türkiye'nin yabanc1 otları ve bazı özellikleri (Weeds of Turkey and their some characteristics). Adana Zirai Mücadele Araştırma Enstitüsü, Adana.

Uluğ, E., Kadıŏlu, İ., 1995. Akdeniz bölgesinde ikinci ürün soya tarlalarındaki yabancı otlar ve mücadele imkânlarının belirlenmesi üzerinde araştırmalar. Bitki Koruma Bülteni, 35(3-4): 211-226.

Uygur, F.N., Koch, W., Walter, H., 1986. Çukurova Bölgesi Buğday-Pamuk Ekim Sistemindeki Önemli Yabanc1 Otların Tanımı. -PLITS 1986/4 (1), Josef Margraf Verlag, Stuttgart, 169 pp.

Uygur, F.N., Köseli, T.F., 1988. A study on allelopathic effect of radish (Raphanus sativus L.) sap on Johnsongrass (Sorghum halepense (L.) Pers.). The Journal of Turkish Phytopathology, 17(3): 136.

Uygur, F.N., Koch, W., 1990. Cynodon dactylon (L.) Pers. ve Sorghum halepense (L.) Pers.'nin tohumlarının çimlenmesini ve rizom boğumlarının sürmesini etkileyen faktörlerin araştırılması. DoğaTurkish Journal of Agriculture and Forestry, 14:192-201.

Uygur, F.N., Köseli, F., Cesurer, L., 1991. Antep turpunun (Raphanus sativus L.) pamuk alanlarında biyoherbisit olarak kullanılma olanaklarının araştırılması. VI. Türkiye Fitopatoloji Kongresi, Türkiye Fitopatoloji Derneği Yayınları No: 6, İzmir, s. $167-171$. 
Üremiş, İ., 2006. Türkiye'de Brassicaceae familyasından bitkilerin allelopatik etkileri üzerine yapılan çalışmalar. Allelopati Çalıştayı, 13-15 Haziran, Yalova, s. 23-35.

Üremiş, İ., Arslan, M., Uludağ, A., Sangün, M.K., 2009a. Allelopathic potentials of residues of 6 brassica species on johnsongrass [Sorghum halepense (L.) Pers.]. African Journal of Biotechnology, 8(15): 3497-3501.

Üremiş, İ., Arslan, M., Sangün, M.K., 2009b. Herbicidal potential of essential oils on the germination of some problem weeds. Asian Journal of Chemistry, 21(4): 3199-3210.

Yazlık, A., 2014. Kanyaş (Sorghum halepense (L.) Pers.)'ı Marmara bölgesindeki yaygınlığı, yoğunluğu, biyolojisi ve alternatif mücadele olanaklarının belirlenmesi. Doktora tezi, Mustafa Kemal Üniversitesi Fen Bilimleri Enstitüsü Bitki Koruma Anabilim Dalı, Hatay.

Zimdahl, R.L., 2007. Fundamentals of weed science [third edition] Academic press, $666 \mathrm{p}$. 